\title{
Crossbreeding to increase beef production: additive and non-additive effects on weight traits
}

\author{
A. Theunissen ${ }^{1,2 \#}$, M.M. Scholtz ${ }^{1,3}$, F.W.C. Neser ${ }^{1}$ \& M.D. MacNeil ${ }^{1,3,4}$ \\ ${ }^{1}$ Department of Animal, Wildlife and Grassland Sciences, UFS, P.O. Box 339, Bloemfontein, 9300, South Africa \\ ${ }^{2}$ Northern Cape Department of Agricultural, Land Reform and Rural Development, Private Bag X9, Jan Kempdorp \\ 8550, South Africa \\ ${ }^{3}$ ARC-Animal Production Institute, Private Bag X2, Irene, 0062, South Africa \\ ${ }^{4}$ Delta G, 145 Ice Cave Rd., Miles City, Montana 59301, USA
}

(Received 12 November 2012; Accepted 6 May 2013; First published online 6 June 2013)

Copyright resides with the authors in terms of the Creative Commons Attribution 2.5 South African Licence.

See: http://creativecommons.org/licenses/by/2.5/za

Condition of use: The user may copy, distribute, transmit and adapt the work, but must recognise the authors and the South African Journal of Animal Science.

\begin{abstract}
Using breed differences effectively facilitates high productivity and profitability. Thus, the objective of the study was to estimate direct and maternal additive and heterosis effects for growth traits (birth weight, weaning weight, 19-month weight of heifers and cow weight) from five purebred and 24 crossbred breed types. Afrikaner (A), Brahman (B), Charolais (C), Hereford (H) and Simmentaler (S) were evaluated as purebreds and as sire breeds on $\mathrm{A}$ and $\mathrm{F}_{1} \mathrm{BA}, \mathrm{CA}, \mathrm{HA}$ and SA females. Breed additive effects were expressed as deviations from A. Effects of intra-breed genetic trend were assumed to be zero throughout. Solutions for the breed additive and heterosis effects were used to predict performance of the crossbred breed types to verify the adequacy of the genetic model. Correlations of observed and predicted means ranged from 0.87 for weaning weight to 0.94 for 19 -month weight. Breed direct effects were consistently greatest for C and least for A across all traits, and maternal effects were greatest for $\mathrm{S}$ (except for 19-month weight) and least for C. Direct and maternal heterosis, on average, were positive for all weights. The indicus x sanga and indicus $\mathrm{x}$ taurus direct heterosis effects on all weight traits were greater than either the taurus $\mathrm{x}$ sanga or taurus $\mathrm{x}$ taurus effects, whereas the indicus $\mathrm{x}$ sanga maternal heterosis effect was consistently less than the estimated taurus $\mathrm{x}$ sanga maternal heterosis effect.
\end{abstract}

Keywords: Direct effects, heterosis, maternal effects, taurus, indicus, sanga

\#Corresponding author: atheunissen@ncpg.gov.za

\section{Introduction}

Crossbreeding systems are employed mainly to improve the efficiency of beef production through the use of heritable difference among breeds and heterosis. Many beef producers derive their income from the total weight of weaned calves. Net income is derived from the value of calves in the marketplace minus the fixed and variable expenses accrued in their production. Net income can be maximized when the optimum number of cows with correct genetic potential (size and milk production) is in harmony with the production environment (MacNeil et al., 1988; Burrow, 2006). Weight traits are not all equally important to efficiency (e.g. MacNeil \& Matjuda, 2007).

Today's sophisticated genetic prediction systems (Green, 2009) enable the use of existing breeding values to model total herd productivity. For crossbreeding, information on breed composition and heterosis are incorporated into multi-breed genetic evaluation models to predict phenotypic performance (Cardoso \& Templeman, 2004; Pollak, 2006). This comes as more commercial cattle producers direct themselves to crossbreeding systems in which crossbred animals have higher merit in reproduction, growth and end product (Spangler, 2007) in a changing environment (Anitei, 2006; Appel, 2006) than their purebred contemporaries. 
The aim of this paper is to estimate breed additive and heterosis effects in South African beef cattle. Data for weight traits of 24 crossbred and five purebred breed types were obtained from Vaalharts Research Station in South Africa from research by Els (1988).

\section{Materials and Methods}

Crossbreeding experiments were carried out at Vaalharts Research Station, near Jan Kempdorp. The

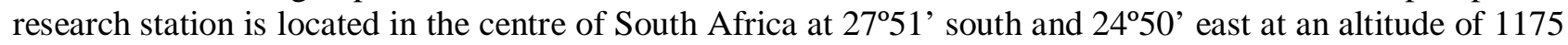
metres and is in an area with sandy red soil with lime rock underneath. These soils form part of the Hutton formation and represent mainly the Manganese series (Laker, 2003). The veld type is mixed Tarchonanthus veld, veld type No 16b, 4 (Acocks, 1988). Vaalharts Research Station has a recommended carrying capacity of $10 \mathrm{ha} / \mathrm{LSU}$. The climate at the research station is characterized by hot summers and cold winters with frost being a common occurrence. The highest monthly average temperature is around $32{ }^{\circ} \mathrm{C}$ and is experienced in December and January. The lowest monthly average temperature is around $-0.5^{\circ} \mathrm{C}$ and is experienced in July. The average rainfall is $450 \mathrm{~mm}$ per annum, of which $88 \%$ is precipitated during the summer months from October to April in the form of thunderstorms.

Els (1988) evaluated five breeds: Afrikaner (A), Brahman (B), Charolais (C), Hereford (H) and Simmentaler (S) as purebreds, as topcrosses on $A$ as a dam line producing $F_{1}$ progeny, and on BA, CA, HA, and $S A F_{1}$ females producing backcross and three-breed cross progenies. The beef cattle herd was raised under extensive conditions. Management and selection procedures of the herd were described by Els (1988). Least squares means, standard errors, and number of records for birth weight (BW), weaning weight (WW), 19-month weight of heifers (HW) and cow weight at partus (CW) of the various breed group combinations were originally presented in Els' thesis (1988). These means were thus adjusted for contemporary group (year of birth, calving season, age of dam) and sex of calf effects, which were significant $(P<0.05)$ sources of variation for all the traits.

Dickerson (1969; 1973) proposed partitioning breed group means into breed-specific additive and heterosis effects as follows:

Pure breeds

$$
\mathbf{C}=\mathbf{G}_{\mathrm{C}}^{\mathrm{I}}+\mathbf{G}^{\mathrm{M}}{ }_{\mathrm{C}}
$$

Two-breed crosses

$$
A \times B=1 / 2 G_{A}^{I}+1 / 2 G_{B}^{I}+H_{A B}^{I}+G^{M}{ }_{B}
$$

Backcrosses

$$
A \times B A=3 / 4 G_{A}^{I}+1 / 4 G_{B}^{I}+1 / 2 H_{B A}^{I}+H^{M}{ }_{B A}+1 / 2 G^{M}{ }_{B}+1 / 2 G^{M}{ }_{A}
$$

Three-breed crosses

$$
A \times B C=1 / 2 G_{A}^{I}+1 / 4 G_{B}^{I}+1 / 4 G_{C}^{I}+1 / 2 \mathbf{H}_{A B}^{I}+1 / 2 \mathbf{H}_{A C}{ }_{A C}+\mathbf{H}^{M}{ }_{B C}+1 / 2 G^{M}{ }_{B}+1 / 2 G^{M}{ }_{C}
$$

In the above formulas: $\mathbf{A}, \mathbf{B}$ and $\mathbf{C}$ designate different breeds, $\mathbf{G}^{\mathbf{I}}$ and $\mathbf{G}^{\mathbf{M}}$ represent individual additive and maternal effects, and $\mathbf{H}^{\mathbf{I}}$ and $\mathbf{H}^{\mathbf{M}}$ represent individual and maternal heterosis effects, respectively. Here, recombination effects were assumed to be nil, and heterosis effects were assumed to be proportional to expected heterozygosity in the crosses relative to the purebreds, and recombination effects were assumed nil. Thus, the general model can be stated as:

$$
\mathbf{Y}=\mathbf{G}_{0}+\beta_{\mathrm{i}} \mathbf{G}^{\mathrm{I}}+\boldsymbol{\beta}_{\mathrm{j}} \mathbf{G}^{\mathrm{M}}+\boldsymbol{\beta}_{\mathrm{k}} \mathbf{H}^{\mathrm{I}}+\boldsymbol{\beta}_{\mathbf{l}} \mathbf{H}^{\mathrm{M}}+\boldsymbol{\varepsilon}
$$

Wherein $\mathbf{Y}$ is the phenotypic value of the cross for the trait interest, $\mathbf{G}_{\mathbf{0}}$ is the intercept, $\boldsymbol{\beta}_{\mathbf{i}}$ and $\boldsymbol{\beta}_{\mathbf{j}}$ are partial regression coefficients representing individual and maternal additive effects, $\boldsymbol{\beta}_{\mathbf{k}}$ and $\boldsymbol{\beta}_{\mathbf{l}}$ are partial regression coefficients representing individual and maternal heterosis effects, and $\boldsymbol{\varepsilon}$ is the residual lack of fit (not estimated).

For each trait, the least squares means reported by Els (1988) for the various breed groups were equated to their respective expectations and the resulting system of equations was solved by weighted least squares, in which the weight given to each mean was the reciprocal of its standard error, using the GLM procedure of SAS (2010). In order to uniquely solve the system of equations represented by the model, two constraints were necessary. These were that $\mathbf{G}_{\mathbf{A}}^{\mathbf{I}}=\mathbf{G}^{\mathbf{M}}{ }_{\mathbf{A}}=0$. Thus, breed-specific individual and maternal additive effects were expressed as deviations from the respective Afrikaner breed effects and the intercept estimated the mean for A. Similar methodology has been used by MacNeil et al. (1988) to summarize 
multiple phases of a crossbreeding experiment, and by Williams et al. (2010) to analyse a number of cattle breeds from an extensive literature review of crossbreeding studies.

An important advantage of partitioning breed effects as described above is that the merit of untested breed combination can be predicted in a straightforward manner from the results (e.g. MacNeil et al., 1988). For instance, the equilibrium value $\left(2 \mathrm{R}_{\mathrm{AH}}\right)$ for the two breed rotation of $\mathrm{A}$ and $\mathrm{H}$ is given by:

$$
2 \mathrm{R}_{\mathrm{AH}}=1 \mathbf{G}_{\mathbf{0}}+1 / 2 \mathbf{G}_{\mathbf{H}}^{\mathbf{I}}+1 / 2 \mathbf{G}^{\mathbf{M}}{ }_{\mathbf{H}}+2 / 3 \mathbf{H}_{\mathrm{AH}}^{\mathrm{I}}+2 / 3 \mathbf{H}^{\mathrm{M}}{ }_{\mathbf{A H}}
$$

Here, predicted values for the breed group means presented by Els (1988) were calculated from the regression model given above as a check on the goodness of fit of the model. For each trait, the correlation between the observed breed group means and their respective predicted values was calculated as a summary statistic.

\section{Results and Discussion}

Although the data analysed here were collected some years ago, it is believed to be reliable and accurate, and the breed group means have been reported previously (Els, 1988). However, it was not analysed in such a way that breed additive and heterosis effects were estimated. The mean level of performance for some of the breeds may have changed as a result of response to selection and/or inbreeding that has accrued in the intervening generations, and this should be considered in contemporary application of these results by the South African beef industry. However, there are no more recent crossbreeding results from data collected under conditions in South Africa.

Pearson's correlation coefficients between the least squares means reported by Els (1988) and their predicted values (not shown) based on the linear model used to partition additive and heterosis effects were calculated to quantify the adequacy of this partitioning (Table 1). These correlation coefficients are all greater than 0.87 , suggesting a high degree of fidelity between the original data and the predicted values derived from the linear model that was used here. Possible explanations for these correlation coefficients being less than 1.0 include genetic effects that were not accounted for in the model (e.g. recombination or epistasis and grand maternal additive effects) and sampling of genetic effects in the breed group means (Williams et al., 2010).

Table 1 Pearson's correlation between the observed least squares means and their predicted values

\begin{tabular}{lc}
\hline Growth traits & Correlation \\
\hline Birth weight & 0.93 \\
Weaning weight & 0.87 \\
19-month heifer weight & 0.94 \\
Cow weight & 0.93 \\
\hline
\end{tabular}

\section{Additive genetic effects}

Estimated breed additive effects for the weight traits are shown in Table 2. The estimated direct effects on weight traits were greater for all breeds involved in the study other than for the A breed, whereas the maternal additive effects were mostly negative, the S breed being an exception. Dickerson (1969; 1973), Wilson et al. (1972) and Schoeman (1999) suggested a possible negative correlation between direct and maternal effects on pre-weaning growth, and posited that those breeds with high estimated individual additive effects would be most suitable as terminal sire breeds in production systems designed to maximize weaning weight, while breeds with high estimated maternal additive effects would be most useful as dam breeds. This latter recommendation may be contrary to best practices in environments where energy is limiting during lactation and breeds with high genetic potential for milk production consequently maintain a negative energy balance that is sufficient to compromise reproduction (Short \& Adams, 1988). 
Table 2 Breed-specific direct and maternal additive effects and standard errors ${ }^{1}$ on weight traits

\begin{tabular}{|c|c|c|c|c|c|}
\hline Effect & Breed $^{2}$ & $\begin{array}{l}\text { Birth weight } \\
(\mathrm{kg})\end{array}$ & $\begin{array}{c}\text { Weaning } \\
\text { weight (kg) }\end{array}$ & $\begin{array}{c}19 \text { month heifer } \\
\text { weight }(\mathrm{kg})\end{array}$ & $\begin{array}{c}\text { Cow weight at } \\
\text { partus (kg) }\end{array}$ \\
\hline Intercept & A mean & $34.5 \pm 0.9 *$ & $184.0 \pm 10.8$ & $303.9 \pm 13.3$ & $435.0 \pm 12.0$ \\
\hline \multirow[t]{4}{*}{ Individual (direct) } & $\mathrm{S}$ & $1.8 \pm 2.8$ & $27.3 \pm 12.9$ & $46.8 \pm 25.0$ & $10.2 \pm 20.5$ \\
\hline & B & $3.0 \pm 3.0$ & $12.4 \pm 12.2$ & $16.3 \pm 21.3$ & $62.6 \pm 18.0$ \\
\hline & $\mathrm{C}$ & $19.6 \pm 5.6$ & $64.1 \pm 26.0$ & $159.0 \pm 52.4$ & $180.1 \pm 43.7$ \\
\hline & $\mathrm{H}$ & $0.1 \pm 3.0$ & $24.7 \pm 13.8$ & $15.3 \pm 24.6$ & $48.8 \pm 20.3$ \\
\hline \multirow[t]{4}{*}{ Maternal } & $\mathrm{S}$ & $7.0 \pm 3.2$ & $22.7 \pm 13.3$ & $8.4 \pm 30.4$ & $13.8 \pm 25.7$ \\
\hline & B & $-4.8 \pm 3.3$ & $2.4 \pm 12.6$ & $12.5 \pm 26.8$ & $-48.6 \pm 22.9$ \\
\hline & $\mathrm{C}$ & $-7.3 \pm 5.8$ & $-25.7 \pm 26.2$ & $-98.3 \pm 56.1$ & $-113.1 \pm 46.8$ \\
\hline & $\mathrm{H}$ & $1.0 \pm 3.3$ & $-29.6 \pm 14.1$ & $-18.1 \pm 31.2$ & $-76.8 \pm 26.1$ \\
\hline
\end{tabular}

Studies have shown that $75 \%$ of calves lost before weaning are lost at or near birth, and that $80 \%$ or more of the deaths result from dystocia or calving difficulties. The birth weight of the calf is the primary determinant of the difficulty of parturition, followed in importance by the pelvic area of the female (Bellows et al., 1971; Short et al., 1979). Older cows are bigger, have larger pelvic openings, and consequently have much fewer calving difficulties than younger cows. Most calving difficulties occur in heifers calving for the first time (Sprott \& Troxel, 2008).

For BW (Table 2) the C had the highest direct breed (individual additive) effect: $+19.6 \mathrm{~kg}$ or $+56.8 \%$. In a study that was performed under an intensive production system at farms in the Johannesburg area, Dadi et al. (2002) found that $\mathrm{C}$ sired calves were $5 \mathrm{~kg}$ heavier than $\mathrm{H}$ sired calves. This sizeable direct effect indicates appropriate use of C sires on older cows (MacNeil et al., 1988), but not on heifers. The other breeds studied had much smaller direct effects on birth weight. In contrast to the large positive direct effect, the maternal additive effect of $C$ on birth weight was $-7.3 \mathrm{~kg}$ or $-21.2 \%$. The $\mathrm{S}$ had the greatest maternal additive effect $(+7.0 \mathrm{~kg}$ or $+20.3 \%)$ of all the breeds involved in the study. This is contrary to the findings of Skrypzeck et al. (2000), who observed a negative maternal effect (-7.2\%) for S in a study that involved the S, $\mathrm{H}$ and $\mathrm{A}$ breeds, and ascribed calving difficulties with $\mathrm{S}$ genotypes is probably the result of the positive breed additive effect on BW. Schoeman et al. (1993) also obtained positive maternal additive effect for S, relative to $\mathrm{A}$ and $\mathrm{H}$. Here, the summed additive effects of S on BW were $+25.5 \%$; substantially greater than the $+10.9 \%$ obtained by Skrypzeck et al. (2000), but closer to the $+17.3 \%$ found by Schoeman et al. (1993). The individual additive effect of B on BW was positive and undesirable (+3.0 kg or $8.7 \%)$, but maternal additive effect of B was $-4.8 \mathrm{~kg}(-13.9 \%)$. Thus, this study reinforced the view that B sired calves, expressing half of the direct effect, but none of the maternal effect, have increased BW (Gregory et al., 1979; Barkhouse et al., 1998) and that B dams, expressing half of the direct effect and all of the maternal effect, produce small calves (Prayaga, 2003).

For many producers, WW represents a saleable product and is thus a point of emphasis. However, the primary objective of applied animal breeding programmes is assumed to be a reduction of total costs per value-unit of products under varying management and marketing situations (Dickerson, 1973). The breed direct effect of C (+64.1 kg or 34.8\%) on WW (Table 2) was greatest among the breeds studied. However, in purebred C, $25.7 \mathrm{~kg}$ of the direct effect was negated by the maternal additive effect, which may be a reflection of lower milk production. Thus, the combined additive contribution of $\mathrm{C}$ was exceeded by $\mathrm{S}$, with $+27.3 \mathrm{~kg}$ direct effect and $+22.7 \mathrm{~kg}$ maternal additive effect. This increase in performance $(+27.2 \%)$ relative to A exceeds the $+21.9 \%$ and $+12.2 \%$ reported by Schoeman et al. (1993) and Skrypzeck et al. (2000), respectively. Based on the sums of the estimated breed direct and maternal effects, WW of both $\mathrm{B}$ and $\mathrm{H}$ calves would be less than either S or C calves, with B calves expected to be $19.7 \mathrm{~kg}$ heavier at weaning than 
H calves. In the North American subtropics, Roberson et al. (1986) found the B direct effect on weaning weight was $12.9 \mathrm{~kg}$ less than $\mathrm{H}$, and the B maternal additive effect was $13.1 \mathrm{~kg}$ greater than $\mathrm{H}$. Similarly, Franke et al. (2001) found the direct effect of $\mathrm{H}$ marginally greater than $\mathrm{B}$, with the direct effects of both breeds being substantially less than C. The corresponding maternal additive effects observed by Franke et al. (2001) indicated H was substantially less than either B or C, which were similar. In studies conducted in the temperate zone, Alenda et al. (1980) and MacNeil et al. (1982) found both direct and maternal additive effects of C greater than $\mathrm{H}$. MacNeil et al. (1982) also found direct effects of C equal to S, and the maternal effect of $\mathrm{S}$ was greater than $\mathrm{C}$. To the extent that differences in breed additive maternal effects reflect differences in milk production (Garrick, 2006), feed requirements of cows may exhibit a corresponding increase. Thus, the economic advantage achieved from increasing WW owing to maternal effects may be somewhat offset by increases in feed cost as reflected in a reduced sustainable stocking rate.

Most breeding systems that produce weaner calves must also produce replacement heifers. To produce a consistent set of replacement heifers, the appropriate crossbreeding system with a particular set of breeds must be consistently maintained (Olsen, 2002). The order of individual additive effects on HW was the same as their order on WW. However, the magnitude of the direct effect of $\mathrm{C}$ relative to A was substantially greater for HW (+52\%) than it was for WW (+35\%), and the magnitude of $\mathrm{H}$ direct effects increased slightly from WW to HW (+5\% vs. $+13 \%)$. The direct effects on HW of B and SH were similar percentagewise to what they had been for WW ( $+5 \%$ and $+15 \%$ vs. $+7 \%$ and $15 \%$, respectively). Maternal additive effects of S and $\mathrm{B}$ were positive and at least marginally greater than the maternal additive effect of $\mathrm{H}$. The maternal additive effect of $\mathrm{C}$ was significantly less than for $\mathrm{S}$ and $\mathrm{B}$ and at least marginally less than for $\mathrm{H}$. Overall, $\mathrm{C}$ and $\mathrm{S}$ heifers would be expected to be heavier at 19 months than $\mathrm{B}$ heifers, with $\mathrm{B}$ heifers being approximately intermediate in weight between $\mathrm{S}$ or $\mathrm{C}$ and $\mathrm{A}$ or $\mathrm{H}$ heifers.

Results from this study also indicated that even for CW, breed maternal effects still exist. In this study $\mathrm{CW}$ was measured at calving (partus). Although $\mathrm{CW}$ at weaning is the more reliable and practical measure to record, Crook et al. (2010) had found an estimated genetic correlation of $0.95 \pm 0.03$ between CW at calving and at weaning of the calf. The maintenance requirement of a cow is affected by her weight: the larger the animal, the greater her maintenance requirement. Therefore, an indicator of cow size may be important in the evaluation of alternative breeding objectives (MacNeil et al., 1984; Garrick, 2006). When compared with the other breeds, A cows were relatively light in weight at parturition and, owing to their relatively low maintenance requirements, are believed to be well adapted to harsh environmental conditions (Moyo et al., 1996). The results presented in Table 2 indicate that $C$ cows would be more than $40 \mathrm{~kg}$ heavier at calving than the other breeds, with S and B cows perhaps slightly heavier and $\mathrm{H}$ cows slightly lighter than A cows at calving. The substantial maternal additive effects observed in this study for HW and CW were contrary to the belief that maternal effects are likely to have little influence on traits measured after the time of weaning. However, Prayaga (2003) and Pico et al. (2004) also found maternal effects affecting postweaning traits, and observed these effects up to final (mature) weight.

\section{Heterosis effects}

Effects of heterosis have important implications, perhaps even more than breed additive effects, for economic efficiency of beef production (Davis et al. 1994). Ehiobu et al. (1990) found that greater theoretical distance based on the co-ancestry of pairs of lines was significantly correlated with heterosis. Thus, greater genetic distance between breeds may result in greater heterosis, relative to more closely related breeds. Contained in this study are representatives of three recognized subspecies of Bos taurus: taurus (C and S) indicus (B), and sanga (A) as well as crosses among them. Thus, there is considerable opportunity for variation in the magnitude of heterosis effects. Estimated heterosis effects found in this study are presented in Table 3. Because the specific breed-cross heterosis effects are estimated from relatively scant amounts of data, the discussion will be focused on the composite estimates from the subspecies.

On average, both direct and maternal heterosis effects were positive for all of the traits examined here. For BW, HW and CW, maternal heterosis effects were less than the corresponding estimates of direct heterosis. Only for WW were the direct and maternal heterosis effects approximately equal. Cundiff et al. (1974) found that maternal heterosis reflected the greater and more persistent milk production crossbred cows over straightbred cows in a study which involved three British breeds. The indicus x sanga and indicus $\mathrm{x}$ taurus direct heterosis effects on all weight traits were greater than either the taurus $\mathrm{x}$ sanga or taurus $\mathrm{x}$ taurus effects, whereas the indicus x sanga maternal heterosis effect was consistently less than the estimated 
taurus x sanga maternal heterosis effect. These results are in accordance with Franke (1994), who reported from crosses between Angus, B, C and H breeds that the direct heterosis effect on BW in crosses with B is higher than in crosses among the Bos taurus breeds. Cundiff et al. (1986) and Arthur et al. (1999) also stated that direct heterosis effects for BW generally range from $1 \%$ to $11 \%$ with values for Bos indicus x Bos taurus at the upper end of the scale.

Table 3 Heterosis effects on weight traits and the associated standard errors ${ }^{1}$

\begin{tabular}{|c|c|c|c|c|c|}
\hline Effect & Breed $^{2}$ & $\begin{array}{c}\text { Birth weight } \\
(\mathrm{kg})\end{array}$ & $\begin{array}{c}\text { Weaning weight } \\
\text { (kg) }\end{array}$ & $\begin{array}{c}19 \text { month heifer } \\
\text { weight }(\mathrm{kg})\end{array}$ & $\begin{array}{l}\text { Cow weight at } \\
\text { partus (kg) }\end{array}$ \\
\hline \multirow[t]{15}{*}{ Individual } & BA & $4.8 \pm 2.1$ & $14.7 \pm 6.9$ & $36.4 \pm 20.5$ & $17.9 \pm 17.8$ \\
\hline & CA & $-3.7 \pm 3.3$ & $1.8 \pm 13.8$ & $-18.0 \pm 33.6$ & $-30.7 \pm 28.3$ \\
\hline & HA & $2.2 \pm 2.1$ & $-0.5 \pm 7.8$ & $23.2 \pm 20.8$ & $-22.1 \pm 18.1$ \\
\hline & SA & $4.6 \pm 2.0$ & $13.0 \pm 7.4$ & $35.0 \pm 21.7$ & $46.5 \pm 18.3$ \\
\hline & $\mathrm{BC}$ & $-2.1 \pm 3.0$ & $24.0 \pm 14.6$ & $39.7 \pm 25.2$ & $44.6 \pm 20.9$ \\
\hline & $\mathrm{BH}$ & $5.7 \pm 2.3$ & $28.0 \pm 11.0$ & $51.2 \pm 15.3$ & $30.2 \pm 13.1$ \\
\hline & BS & $3.8 \pm 2.2$ & $36.7 \pm 10.6$ & $71.7 \pm 17.3$ & $82.2 \pm 14.5$ \\
\hline & $\mathrm{CH}$ & $-3.5 \pm 3.1$ & $0.0 \pm 14.8$ & $-10.2 \pm 25.9$ & $-27.1 \pm 21.4$ \\
\hline & CS & $-1.3 \pm 3.0$ & $6.1 \pm 14.3$ & $-23.1 \pm 26.9$ & $9.5 \pm 22.4$ \\
\hline & HS & $1.6 \pm 2.2$ & $22.7 \pm 10.8$ & $43.1 \pm 18.3$ & $39.5 \pm 14.7$ \\
\hline & indicus x sanga & 4.8 & 14.7 & 36.4 & 17.9 \\
\hline & taurus x sanga & 1.1 & 4.8 & 13.4 & 2.1 \\
\hline & indicus $\mathrm{x}$ taurus & 2.5 & 29.3 & 54.2 & 52.3 \\
\hline & taurus $\times$ taurus & -1.1 & 9.6 & 3.3 & 7.3 \\
\hline & Average & 1.2 & 14.7 & 24.9 & 19.1 \\
\hline \multirow[t]{7}{*}{ Maternal } & BA & $-2.4 \pm 1.4$ & $5.5 \pm 5.8$ & $-16.2 \pm 9.5$ & $-10.6 \pm 8.1$ \\
\hline & CA & $6.9 \pm 2.5$ & $30.7 \pm 11.4$ & $58.2 \pm 23.6$ & $54.8 \pm 19.4$ \\
\hline & HA & $-0.2 \pm 1.4$ & $22.1 \pm 5.9$ & $15.6 \pm 12.3$ & $22.8 \pm 10.2$ \\
\hline & SA & $-2.2 \pm 1.3$ & $6.2 \pm 5.4$ & $2.3 \pm 11.8$ & $-16.8 \pm 9.7$ \\
\hline & indicus x sanga & -2.4 & 5.5 & $\begin{array}{c}-16.2 \\
203\end{array}$ & $\begin{array}{l}-10.6 \\
203\end{array}$ \\
\hline & taurus x sanga & 1.5 & 19.7 & 20.3 & 20.3 \\
\hline & Average & 0.5 & 16.1 & 15.0 & 12.6 \\
\hline
\end{tabular}

${ }^{1}$ The standard errors represent lack of fit to the genetic model, rather than variation among animals with similar breed composition.

${ }^{2} \mathrm{~A}=$ Afrikaner; $\mathrm{B}=$ Brahman; $\mathrm{C}$ = Charolais; $\mathrm{H}$ = Hereford; $\mathrm{S}=$ Simmentaler.

indicus $=$ Brahman; taurus $=$ Charolais, Hereford, Simmentaler; sanga $=$ Afrikaner .

Predicted performance levels

Table 4 shows predicted performance levels for many of the breed crosses produced in this study. Progeny from the A sire line had the lightest average BW $(37.1 \mathrm{~kg})$ among the five breeds. Progeny of BA crossbred cows had, on average, the lightest predicted BW among the dam lines. Backcrossing crossbred dams decreased $\mathrm{BW}$ in $\mathrm{A}(\mathrm{BA}), \mathrm{B}(\mathrm{BA})$ and $\mathrm{S}(\mathrm{SA})$ breed combinations, remained constant in the $\mathrm{H}(\mathrm{HA})$, but increased in the $\mathrm{C}(\mathrm{CA})$ backcross relative to the respective $\mathrm{F}_{1}$ breed combinations. The $\mathrm{A}(\mathrm{BA})$ breed combination provided the least expected phenotypic value of BW of all 19 crossbred combinations. Calves sired by $\mathrm{C}$ were predicted to be heaviest, followed by B sired calves. 
Table 4 Predicted phenotypic values for weight traits of calves produced by different sire and dam breed groups

\begin{tabular}{llllll}
\hline \multirow{2}{*}{ Dam breeds } & \multicolumn{4}{c}{ Sire breeds } & \\
\cline { 2 - 5 } Afrikaner (A) & Brahman (B) & Charolais (C) & Hereford (H) & Simmentaler (S) & \\
\hline
\end{tabular}

Birth weight, kg

\begin{tabular}{ccccccc} 
A & $(34.5)$ & 40.8 & 40.6 & 36.7 & 42.6 & 40.2 \\
BA & 34.1 & 35.6 & 40.1 & 35.5 & 35.4 & 35.6 \\
CA & 37.4 & 45.5 & 47.1 & 42.1 & 45.2 & 43.5 \\
HA & 35.0 & 41.5 & 37.7 & 36.8 & 35.9 & 38.7 \\
SA & 41.8 & 46.5 & 44.8 & 37.8 & 40.5 & 41.4 \\
\hline Average & 37.1 & 41.1 & 42.2 & 37.8 & 40.6 & \\
\hline
\end{tabular}

Weaning weight, $\mathrm{kg}$

\begin{tabular}{ccccccc} 
A & $(184.0)$ & 205.0 & 217.9 & 196.1 & 210.7 & 207.4 \\
BA & 198.4 & 204.7 & 239.2 & 224.9 & 232.4 & 219.9 \\
CA & 203.4 & 243.4 & 235.9 & 229.9 & 241.1 & 230.7 \\
HA & 186.2 & 225.0 & 230.8 & 198.6 & 229.1 & 213.9 \\
SA & 211.8 & 251.9 & 245.3 & 231.9 & 225.5 & 233.3 \\
\hline Average & 200.0 & 226.0 & 233.8 & 216.3 & 227.8 & \\
\hline
\end{tabular}

Heifer weight, kg

\begin{tabular}{ccccccc} 
A & $(303.9)$ & 348.5 & 365.4 & 334.8 & 362.3 & 352.8 \\
BA & 324.3 & 332.5 & 388.4 & 342.9 & 374.8 & 352.6 \\
CA & 314.6 & 398.9 & 394.1 & 363.0 & 382.1 & 370.5 \\
HA & 318.1 & 366.2 & 379.7 & 325.8 & 376.7 & 353.3 \\
SA & 338.5 & 384.3 & 381.1 & 358.7 & 361.9 & 364.9 \\
\hline Average & 323.9 & 366.1 & 381.7 & 345.0 & 371.6 & \\
\hline Cow weight, kg & & & & & & \\
A & $(435.0)$ & 484.2 & 494.4 & 437.3 & 486.6 & 475.6 \\
BA & 427.2 & 458.5 & 512.8 & 444.2 & 533.8 & 475.3 \\
CA & 435.5 & 540.8 & 525.6 & 478.1 & 511.4 & 498.3 \\
HA & 405.6 & 487.0 & 492.8 & 430.0 & 479.7 & 459.0 \\
SA & 468.9 & 509.0 & 507.1 & 455.8 & 474.0 & 483.0 \\
\hline Average & 434.3 & 495.9 & 506.5 & 449.1 & 497.1 &
\end{tabular}

( ) Not included in the average.

Progeny of CA crossbred cows had the greatest BW of all two-breed dams. All crossbred breed groups were predicted to wean heavier calves than purebred A. Progeny of $C$ sires were expected to be heaviest at weaning, whereas the SA dam line was predicted to produce the heaviest weaned calves among the dam lines evaluated. On average, the A sire lines were expected to produce the lightest calves at weaning. On average, SA dams were predicted to wean the heaviest calves with the B(SA) topcross providing the greatest expected phenotypic value for WW. Relative to the F1 breed combinations, backcrosses to the A sire line decreased WW in $\mathrm{A}(\mathrm{BA}), \mathrm{A}(\mathrm{CA})$ and $\mathrm{A}(\mathrm{HA})$, but not in $\mathrm{A}(\mathrm{SA})$. Backcrossing the other crossbred dam meant that improved weaning performance was predicted for all but the $\mathrm{B}(\mathrm{BA})$ breed combination. On average, all breeds of sire were predicted to produce heavier heifers than $\mathrm{A}$, with $\mathrm{B}$ and $\mathrm{H}$ sired heifer being intermediate 
between $\mathrm{A}$ and the heaviest $\mathrm{S}$ and $\mathrm{C}$ sired heifers. Backcrossing crossbred females increased predicted HW in $\mathrm{C}(\mathrm{CA})$ and $\mathrm{H}(\mathrm{HA})$, did not change predicted $\mathrm{HW}$ in the $\mathrm{S}(\mathrm{SA})$, and reduced predicted $\mathrm{HW}$ in $\mathrm{B}(\mathrm{BA})$ relative to the respective $F_{1}$ breed combinations. All but the $\mathrm{A}(\mathrm{HA})$ and $\mathrm{H}(\mathrm{HA})$ breed combinations in this study had greater expected phenotypic values for CW at partus compared with purebred A dams (435 kg). On average, the B, C, H and S sire line genotypes had 14.2\%, 16.6\%, 3.4\% and $14.5 \%$ increased CW, respectively, compared with $\mathrm{A}$ sire line genotypes. The $\mathrm{B}(\mathrm{CA})$ topcross had the greatest predicted $\mathrm{CW}$ among the breed combinations. Backcrossing two-breed cross dam lines to the A sire line consistently decreased predicted $\mathrm{CW}$ relative to $\mathrm{F}_{1}$ cross females. Backcrossing two-breed dam lines to $\mathrm{S}$ and $\mathrm{B}$ sire lines increased CW and backcrossing to $\mathrm{H}$ and $\mathrm{C}$ decreased predicted $\mathrm{CW}$. The observed superiority of some of the backcrosses relative to $F_{1}$ and topcross is a reflection of the need to appropriately account for the tradeoff between breed additive effects and heterosis in seeking to maximize performance through crossbreeding (Gregory \& Cundiff, 1980).

\section{Conclusions}

As terminal sires, $\mathrm{C}$ would be expected to sire the heaviest calves at birth, with $\mathrm{B}, \mathrm{H}$ and $\mathrm{S}$ siring calves of similar birth weight to A. Similarly, C sired calves would be heaviest at weaning among the breeds studied here. Topcross calves sired by $\mathrm{S}$ and $\mathrm{H}$ would be expected to be heavier than cohorts sired by $\mathrm{A}$.

The magnitude of the individual heterosis effects associated with $\mathrm{B}$ crosses is indicative of their use as a sire breed. The substantial positive direct effect of $\mathrm{C}$ on $\mathrm{CW}$, coupled with its negative maternal additive effect on WW, make $\mathrm{C}$ an unlikely contributor to dam lines. Consistent with the earlier recommendation of Neser et al. (2003), these data indicate $S$ as a desirable contributor to dam lines under conditions sufficiently favourable to support their increased level of milk production. Future work should explore the applicability of these findings to contemporary circumstances and effects of the differences observed here on production efficiency.

\section{Acknowledgement}

This article forms part of a MSc study by the first author. This research is supported financially by RMRD SA (Red Meat Research and Development South Africa) and THRIP (Technology and Human Resources for Industry Programme). The dedication of the late D. Els, who summarized and analysed this extensive dataset statistically, and the excellent work by the researchers at Vaalharts Research Station in collecting the data are acknowledged.

\section{References}

Acocks, J.P.H., 1988. Veldtypes of South Africa. Memoirs of the Botanical Survey of South Africa. Botanical Research Institute. Pretoria.

Alenda, R., Martin, T.G., Lasley, J.F. \& Ellersieck, M.R., 1980. Estimation of genetic and maternal effects in crossbred cattle of Angus, Charolais and Hereford parentage. I. Birth and weaning weights. J. Anim. Sci. 50, 226-234.

Anitei, S., 2006. The effects of global warming in Africa. Available at: ttp://news.softpedis.com

Appel, A., 2006. Global warming may dry up Africa's rivers, study suggests. Available at: http://news.nationalgeographic.com/news/2006/03/03033_060303_africa.html

Arthur, P.F., Hearnshaw, H. \& Stephenson, P.D., 1999. Direct and maternal additive and heterosis effects from crossing Bos indicus and Bos taurus cattle: cow and calf production in two environments. Livest. Prod. Sci. 57, 231-241.

Barkhouse, K.L., Van Vleck, L.D., Buchanan, D.S. \& Marshall, D.M., 1998. Comparison of sire breed solutions for growth traits adjusted by mean expected progeny differences to a 1993 base. J. Anim. Sci. 76, 2287-2293.

Bellows, R.A., Short, R.E., Anderson, D.C., Knapp, B.W. \& Pahnish, O.F., 1971. Cause and effect relationships associated with calving difficulty and calf birth weight. J. Anim. Sci. 33, 407-415.

Burrow, H.M., 2006. Utilization of diverse breed resources for tropical beef production. $8^{\text {th }}$ World Congress on Genetics Applied to Livestock Production, Belo Horizonte, MG, Brazil.

Cardoso, F.F. \& Templeman, R.J., 2004. The value of hierarchical Bayes models on genetic evaluation of multiple-breed beef cattle populations. J. Anim. Sci. 83, 62-72. 
Crook, B.J., Neser, F.W.C. \& Bradfield, M.J., 2010. Genetic parameters for cow weight at calving and at calf weaning in South African Simmental cattle. Http://www.scielo.org.za/scielo.php?script=sci

Cundiff, L.V., Gregory. K.E., Schwulst, F.J. \& Koch, R.M., 1974. Effects of heterosis on maternal performance and milk production in Hereford, Angus and Shorthorn cattle. J. Anim. Sci. 38, 728-745.

Cundiff, L.V., Gregory, K.E., Koch, R.M. \& Dickerson, G.E., 1986. Genetic diversity among cattle breeds in its use to increase beef production efficiency in a temperate environment. Proc. $3^{\text {rd }}$ World Cong. Genet. Appl. Livest. Prod. IX, 271.

Dadi, H., Jordaan, G.F., Schoeman, S.J. \& Van der Westhuizen, J., 2002. The effect of Charolais and Hereford sires and straightbred and crossbred dams on pre-weaning growth of calves. S. Afr. J. Anim. Sci. 32, 38-43.

Davis, K.C., Tess, M.W., Kress, D.D., Doornbos, D.E. \& Anderson, D.C., 1994. Life cycle evaluation of five biological types of beef cattle in a cow-calf range production system: II. Biological and economic performance. J. Anim. Sci. 72, 2591-2598.

Dickerson, G.E., 1969. Experimental approaches in utilizing breed resources. Anim. Breed. Abstr. 37, 191-202.

Dickerson, G.E., 1973. Inbreeding and heterosis in animals. In: Proc. Of Anim. Breed \& Genet. Symposium in Honor of Dr. J.L. Lush, Chapaign. Illinois. Amer. Soc. Anim. Sci. 54-77.

Ehiobu, N.G., Goddard, M.E. \& Taylor, J.E., 1990. Prediction of heterosis in crosses between inbreed lines of Drosophila melanogaster. Theoretical and Applied Genetics 80, 321-325.

Els, D.L., 1988. Kruisteling vir Vleisproduksie. PhD thesis, University of the Free State, South Africa.

Franke, D.E., 1994. Genetic effects for beef cattle pre-weaning traits. Proc. $5^{\text {th }}$ World Cong. Genet. Appl. Livest. Prod. 17, 296 (Guelph, Canada).

Franke, D.E., Habet, O., Tawah, L.C., Williams, A.R. \& DeRouen, 1981. Direct and maternal genetic effects on birth and weaning traits in multibreed cattle data and predicted performance of breed crosses. J. Anim. Sci. 79, 1713-1722.

Garrick, D.J., 2006. Genetic improvement of beef cattle - assessing the ramifications of genetic change. $8^{\text {th }}$ World congress on Genetics Applied to Livestock Production, August 13-18. Belo Horizonte. MG, Brazil.

Green, R.D., 2009. ASAS Centennial paper: Future needs in animal breeding and genetics. J. Anim. Sci. 87, 793-800.

Gregory, K.E. \& Cundiff, L.V., 1980. Crossbreeding in beef cattle: Evaluation of systems. J. Anim. Sci. 51, 1224-1242.

Gregory, K.E., Smith, G.M., Cundiff, L.V., Koch, R M. \& Laster, D.B., 1979. Characterization of biological types of cattle - cycle III: Birth and weaning traits. J. Anim. Sci. 48, 271-279.

Laker, M.C., 2003. Soil Classification. A global desk reference. Print ISBN: 978-0-8493-1339-4. CRC Press.

MacNeil, M.D. \& Matjuda, L.E., 2007. Breeding objectives for Angus and Charolais specialized sire lines for use in the emerging sector of South African beef production. S. Afr. J. Anim. Sci. 37, 1-7.

MacNeil, M.D., Dinkel, C.A. \& Van Fleck, L.D., 1982. Individual and maternal additive and heterotic effects on 205-day weight in beef cattle. J. Anim. Sci. 54, 951-956.

MacNeil, M.D., Cundiff, L.V., Dinkel, C.A. \& Koch, R.M., 1984. Genetics correlations among sex-limited traits in beef cattle. J. Anim. Sci. 58, 1171-1180.

MacNeil, M.D., Cundiff, L.V. \& Gregory, K.E., 1988. Crossbreeding systems for beef production. Appl. Agric. Res. 3, 44-54.

Moyo, S., Swanepoel, F.J.C. \& Rege, J.E.O., 1996. Evaluation of indigenous , exotic and crossbred cattle for beef production in a semi-arid environment: reproductive performance and cow productivity. Proc. Aust. Soc. Anim. Prod. 21, 204-206.

Neser, F.W.C., Van Wyk, J.B. \& Erasmus, G.J., 2003. Performance of Simmentaler cattle in South Africa: a scientific review. Http://www.wsff.info/files/congress

Olsen, T.A., 2002. Crossbreeding programs for beef cattle in Florida. BUL 326/AN055. Http://edis.ifas.ufl.edu/an055

Pico, B.A., Neser, F.W.C. \& Van Wyk, J.B., 2004. Genetic parameters for growth in South African Brahman cattle. S. Afr. J. Anim. Sci. 34, 44-46.

Pollak, E.J., 2006. Multibreed genetic evaluations of beef cattle in the United States. $8^{\text {th }}$ World Congress on Genetics Applied to Livestock production, Belo Horizonte, MG, Brazil. 
Prayaga, K.C., 2003. Evaluation of beef cattle genotypes and estimation of direct and maternal genetic effects in a tropical environment. 1. Growth traits. Aust. J. Agric. Res. 54, 1013-1025.

Roberson, R.L., Sanders, J.O. \& Cartwright, T.C., 1986. Direct and maternal genetic effects on pre-weaning characters of Brahman, Hereford and Brahman-Hereford crossbreed cattle. J. Anim. Sci. 63, 438-446.

SAS, 2010. Statistical Analysis System. Cary, North Carolina USA.

Schoeman, S.J., 1989. Recent research into production potential of indigenous cattle with special reference to Sanga (Review). S. Afr. J. Anim. Sci. 19, 55-61.

Schoeman, S.J., 1999. Crossbreeding in beef cattle. In: Beef Breeding in South Africa. Eds Scholtz, M.M., Berg, L. \& Bosman, D.J., Agricultural Research Council, Animal Improvement Institute Irene, South Africa.

Schoeman, S.J., Van Zyl, J.G.E. \& De Wet, R., 1993. Direct and maternal additive and heterotic effects in crossbreeding Hereford, Simmentaler and Afrikaner cattle. S. Afr. J. Anim. Sci. 23, 61-71.

Short, R.E. \& Adams, D.C., 1988. Nutritional and hormonal interrelationships in beef cattle reproduction. Can. J. Anim. Sci. 68, 29-39.

Short, R.E., Bellows, R.A., Staigmiller, R.B., \& Carr, J.B., 1979. Multiple linear and nonlinear regression analyses of factors causing calving difficulty. Theriogenology 12, 121-130.

Skrypzeck, H., Schoeman, S.J., Jordaan, G.F. \& Neser, F.W.C., 2000. Estimates of crossbreeding parameters in a mutibreed beef cattle crossbreeding project. S. Afr. J. Anim. Sci. 3, 193-204.

Spangler, M.L., 2007. The value of heterosis in cow herd: lessons from the past that apply to today. Range Beef Cow Symposium, Univ. Nebraska, Lincoln. Available at: http://Fdigitalcommons.unl.edu/rangebeefsowsyp/21

Sprott, L.R. \& Troxel, T.R., 2008. Management of replacement heifers for high reproduction and calving rate. Http://animalscience.tamu.edu

Williams, J.L., Aguilar, I., Rekaya, R. \& Bertrand, J.K., 2010. Estimation of breed and heterosis effects for growth and carcass traits in cattle using published crossbreeding studies. J. Anim. Sci. 88, 460-66.

Wilson, L.L., Rishel, W.H. \& Harvey, W.R., 1972. Influence of herd, sire and herd x sire interactions on live and carcass characters of beef cattle. J. Anim. Sci. 35, 502-506. 